\title{
RESERVOIR OPERATION USING HYBRID OPTIMIZATION ALGORITHMS
}

\author{
HO V.H. ${ }^{1}$ \\ KOUGIAS I. ${ }^{2}$ \\ KIM J.H. ${ }^{3, *}$
}

\author{
${ }^{1}$ Southern Institute of Water Resources Research \\ 658 Vo Van Kiet str., Dist. 5, Hochiminh City, Vietnam \\ ${ }^{2}$ Renewables and Energy Efficiency Unit \\ Institute for Energy and Transport, European Commission \\ Joint Research Centre, Ispra, Italy \\ ${ }^{3}$ School of Civil, Environmental and Architectural Engineering \\ Korea University Anam-Dong, Seongbuk-Gu \\ Seoul, 136-713, Republic of Korea
}

Received: $27 / 06 / 2014$

Accepted: 25/11/2014

*to whom all correspondence should be addressed:

Available online: 03/12/2014

\begin{abstract}
In the present paper, the authors present a new hybrid optimization technique toward optimum reservoir planning and operation. The basis of the developed hybrid algorithms is the combination of harmony search (HS) and incremental dynamic programming (IDP). This resulted in the development of a new algorithm and two variants, all of which are described in detail. The algorithms were used for optimally operating the Huong Dien hydroelectric dam, located in the Hue Basin in central Vietnam.

Initially, the authors designed the model that describes the water balance equation and the operation of the hydroelectric station. The developed algorithms were then used for defining the optimum reservoir operation (ORO), using observed records of the years 1997-2005. The aims of ORO include maximum hydropower energy production, flood prevention and ensuring drinking/irrigation water availability.

In addition to that, the present study investigated probable future alterations in the reservoir's operation. The hybrid algorithm that showed the best performance in the first phase was selected for processing meteorological data of different future climate scenarios (2020-2039). Following the calibration of the climate model on observed data, the created hybrid method optimized the operation of Huong Dien reservoir, indicatively for the target-year 2020. Finally, the ranges of the decision variables that result in the best management have been defined, offering a framework for efficient scheduling under environmental change.
\end{abstract}

Keywords: Reservoir Operation, Water Resources Management, Hybrid Optimization Algorithms, Harmony Search, Hydropower, Climate Change.

\section{Introduction}

Water is a vital resource for the socio-economic development of river-basin areas. Hydropower, which is an efficient and reliable source of energy, contributes to significant reductions in carbon dioxide emissions. Hydropower has a main role in the energy sector of Vietnam, covering almost $40 \%$ of the annual energy needs. However, advanced planning and management is needed more than ever, to soothe certain issues and recent problems.

According to the public opinion in Vietnam, water release rates from hydropower dams were responsible 
for the flood events after two successive storm events in September and November 2009. This notion reappeared in November 2013, when flood waters rose quickly after 15 hydropower plants opened their sluice gates as a safety measure. The increased frequency of flood events, mostly between October and December, has resulted in casualties and major economic losses (UN Situation Report, 2013). At the same time, water shortage during the dry season (from May to July) is an additional issue for the local economy, with adverse effects.

\subsection{Reservoir operation}

Reservoir operation includes the decision-making regarding water resources allocation to the different users. It is a complex procedure that involves several decision variables, risk and uncertainty. Most reservoirs serve multiple purposes. Thus, a need to address multiple, often conflicting, objectives arises. Reservoir operators address these challenges using numerical analysis and optimization methods. They try to define a framework for water release rates according to the current situation of the reservoir (water level, hydrology, energy prices, drinking water demand, irrigation etc.).

Considering possible alterations of the status of the reservoir can be very helpful for future planning and risk management. Climate models can offer an insight to the future hydrology of river basins. Accordingly, the present study investigates reservoir operation strategies, by setting two main targets. Firstly, it develops an efficient hybrid optimization technique, by combining a mathematical optimization method with a modern metaheuristic algorithm. Fulfilling its second target, it develops a framework, in which a climate model is coupled with the simulation/optimization model, in order to optimize the decision variables in the future operation of the reservoir.

The framework is applied on the Huong Dien reservoir in the Hue River basin, Vietnam, where hydroelectric energy production and flood mitigation are the main objectives.

\subsection{Related Work: Optimization techniques in reservoir management}

The idea of using numerical methods for ORO is not new. Very early linear (LP) and dynamic programming (DP) were applied for the ORO of reservoir models (Hall and Shepherd 1967; Hall et al. 1968). Larson, who introduced Incremental DP (1968), proposed short-term and long-term planning strategies for multi-unit reservoirs, using DP (Larson and Keckler, 1969). Based on this work, Chow and Cortes-Rivera (1974) optimized a demanding reservoir system using discrete differential DP. The novelty was that inflows and constraints could take continuous values and, contrary to previous work, they were not discrete. This alteration resulted in a considerably wider search space and thus to a more challenging task. Murray and Yakowitz (1979) formulated a large-scale, ten-reservoir problem, where size and number of constraints increased complexity. The multi-reservoir control was achieved using constrained differential DP. In 1981, Turgeon presented a comprehensive analysis for long-term reservoir scheduling, focusing on reservoirs connected in series. His analysis included operation optimization with the use of DP. Stedinger et al. (1984) used Stochastic DP to optimize the reservoir operation of an Aswan dam, in Nile river basin. The novelty in their approach was the use of the best inflow forecast, instead of the preceding period's inflow. Karamouz et al. (1992) used a stochastic optimization scheme to define the operating rules of a multiple reservoir system in a two-river system under a set of 28 different constraints.

Progress in the field of metaheuristics led to their application in complex reservoir operation problems. An application of Genetic Algorithms (GA) by Wardlaw and Sharif (1999) solved several problems, outperforming known solutions. Mantawy et al. (2003) used Simulated Annealing (SA) for optimum hydroscheduling of a multi-reservoir hydropower plant connected in series on a river. In their case study, which was initially presented by Turgeon (1981), the SA converged to advanced results. Later on, Kumar and Reddy (2006) developed an Ant Colony Algorithm for multi-purpose reservoir operation in India. Their research included a comparison with findings obtained by GA, arguing that Ant-Colony outperformed GA. The application of metaheuristics to reservoir planning has then been sustained. Thus, recently developed methods such as Honey-Bee Algorithm (Afshar et al., 2007) and Harmony Search (Geem, 2006; Kougias \& Theodossiou, 2013) have also been applied to ORO problems. 
Efforts to develop hybrid techniques include the work of Tospornsampan et al. (2005), where Genetic Algorithms and discrete differential dynamic programming (DDDP) were combined for optimizing the operation of multi-reservoir systems. They created the GA-DDDP stating that it converges into optimal values but requires more computation time. An effective hybrid approach for dealing with multible objectives of hydrological models has been presented by Efstratiadis and Koutsoyiannis (2008), who devised a hybrid algorithm using SA and the downhill Simplex method.

\section{Optimization of the reservoir operation model}

In this section the created hybrid, harmony-based algorithm used for optimal reservoir operation is presented. Considering the advantages of Harmony Search (HS) algorithm and its successful application to several water-related problems, a hybrid algorithm that combines HS and Incremental DP has been developed. Two associated variants have also been created, in order to investigate the possibility for further improvement of the method. These algorithms include a third stage, where a HS or GA, respectively, operates.

The created method and its variants have been applied to define the optimum scheduling and operation of a hydropower reservoir in Vietnam. A main aim was to maximize benefits derived from hydropower production. Figure 1 shows the structure of the Optimal Reservoir Operation model, created for the present analysis.

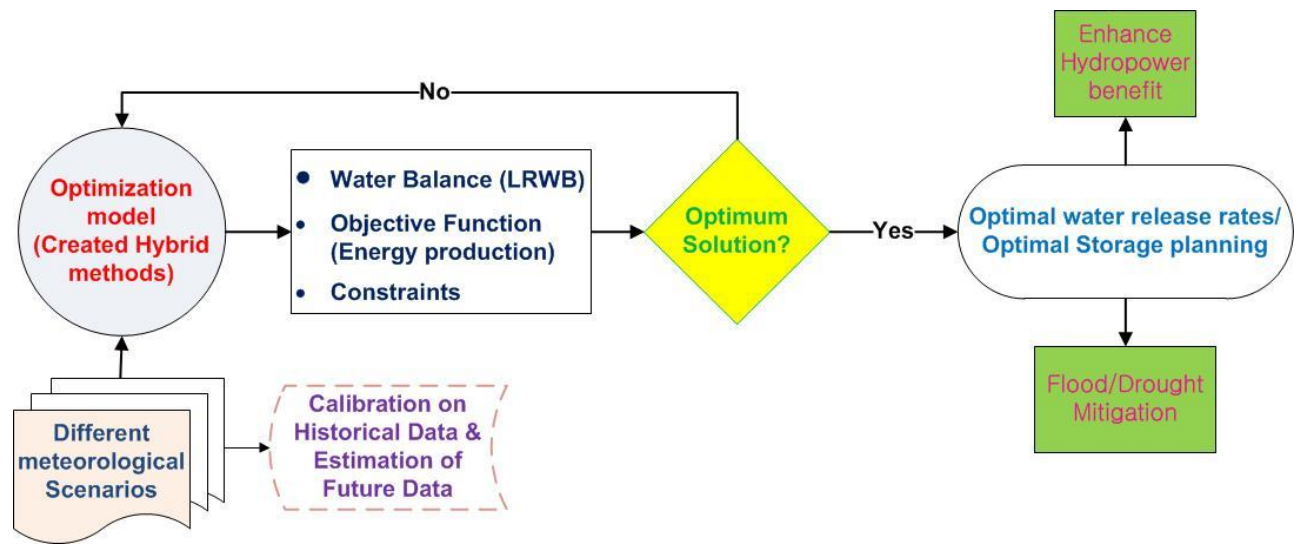

Figure 1. Flowchart of optimal reservoir operation (ORO) model

Water inflow data, either historical or predicted, are input to the created ORO model. Then, the created hybrid technique (HS-IDP) or any of its variants optimizes the hydropower production (HP) objective function, in respect to the linear water balance equation (LRWB). Thus, the values of the decision variables corresponding to optimum reservoir management are detected. Obviously, solutions need to satisfy all constraints associated with the problem. Constrained optimization problems are generally difficult to deal with because the constraints might divide the search space in discrete, remote "islands". In this research, new solutions violating constraints still get a chance to be stored, in order to act as material for optimum solution production in future iterations. These solutions are added a penalty.

The ORO model keeps running until the stopping criterion is satisfied. The best solutions detected offer alternative strategies leading to optimal reservoir management through the enhancement of Hydropower benefit and flood mitigation.

The parameters of the created model are:

- Re: water release rate through turbines (decision variables)

- S: volume of stored water

- H: reservoir's water level 
- I: inflow rate

- O: release rate (spillway)

- Ev: evaporation

- If: infiltration.

Given that the system comprises one reservoir, the number of decision variables $\mathrm{Re}$ is equal to the number of time-steps $\mathrm{N}$.

\subsection{Optimization algorithms}

\subsubsection{Harmony Search algorithm (HS)}

Geem et al., (2001) introduced the harmony search (HS) algorithm inspired by the process of music creation. This optimization technique has already been successfully implemented in various applications, for problems from different scientific fields.

HS algorithm initially creates a vector with randomly generated candidate solutions. The size of the vector is one of HS's parameters and is called harmony memory size. Along with the decision variables' values, harmony memory includes the corresponding value of the objective function, which is used for evaluating the quality of the candidate solutions.

HS creates components of candidate solution based on three mechanisms:

1. Memory Consideration: The components' value can be selected from stored solutions in harmony memory, with a probability equal to HMCR\%. This parameter, named harmony memory consideration rate, is defined by the user.

2. Pitch Adjustment: Every component chosen from stored solutions is likely to be adjusted, i.e. altered to a neighbouring value. This procedure is the local-search mechanism and the pitch adjustment rate (PAR\%) indicates its probability.

3. Random Selection: Random choice of values from possible value range occurs instead of memory consideration, with a probability equal to (100-HMCR)\%.

\subsubsection{Incremental Dynamic Programming (IDP)}

IDP uses the recursive equation of dynamic programming, which is presented in Equation 1. IDP searches for an improved trajectory starting from an assumed feasible solution, which serves as a trial trajectory. The algorithm then seeks improved trajectories within the pre-specified range, known as "temporal memory". The computation process is completed when IDP fulfils a pre-specified convergence criterion.

In the present application, the number of stages is equal to the number of time-steps of the model $(n=12$ months). Thus, for every state of the optimization process, a new possible solution is generated, which is expressed by the following equation:

$$
F_{j}^{*}\left(S_{j}^{N e w}, \operatorname{Re}_{j}^{N e w}\right)=\max \left[F_{j}\left(S_{j}^{N e w}, \operatorname{Re}_{j}^{N e w}\right)+F_{j}^{*}\left(S_{j+1}^{N e w}, \operatorname{Re}_{j+1}\right)\right]
$$

Where:

$F_{j}$ is the economic benefits derived from the station's operation during period $j$

$F_{j}{ }^{*}$ is the accumulated benefit of the periods between months $j$ (or $j+1$ ) to 12

$\mathrm{S}_{\mathrm{j}}$ is the stored water volume at the time step $\mathrm{j}$

$\mathrm{Re}_{\mathrm{j}}$ is the released water volume (decision variables)

In IDP, decisions include water releases and stored water in stage $\mathrm{j} . \mathrm{S}_{\mathrm{j}}^{\mathrm{New}}$ can assume three incremental values: $S_{j} ; S_{j}+\Delta$ or $S_{j}-\Delta$, with $\Delta \in\left[0.5-1 \cdot 10^{6} m^{3}\right] . F_{j}$ represents the benefit, i.e., the value of the objective function that corresponds to the decision variables at a specific stage. $F_{j}^{*}$ is the accumulated benefit. The stopping criterion is expressed by Eq.2: 


$$
\left(F_{j}-F_{j-1}\right) / F_{j-1} \leq 0.0002
$$

Where:

F values correspond to the economic benefits derived from the station's operation during periods $j-1$ and j

According to Equation 2, when two consecutive evaluations are almost identical, the process terminates.

\subsubsection{Genetic Algorithms (GA)}

Genetic algorithms are a metaheuristic optimization technique inspired from the principles of natural selection, evolution, and genetics that has been widely applied to many scientific fields (Holland, 1975). In Genetic Algorithms chromosomes correspond to decision variables, which in the present model are the water storage values. GAs imitate natural selection processes to locate values of the decision variables that optimize the objective function. In order to succeed that, they perform algorithmic mechanisms such as Selection, Crossover and Mutation. Thus, following the initial creation of a population of solutions (chromosomes), a selection process (roulette) chooses those dominant chromosomes that can generate evolved offspring. In the reproduction process, crossover is implemented by exchanging parts of chromosomes (solution components) among the selected parents. Mutation mechanism alters only one (or very few) of the solution components, preventing the solutions from becoming too similar to each other. Crossover and Mutation are the basic mechanism of the GAs for global and local search, while searching quality solutions.

\subsection{Created hybrid algorithms}

\subsubsection{Hybrid HS-IDP}

The HS-IDP hybrid algorithm was developed in the present study to act as an effective tool for the optimal operation of the Huong Dien reservoir. Its objective is to locate monthly water release rates that result in maximum benefits and optimal reservoir management.

HS-IDP aims to improve IDP's performance. In the proposed scheme, the HS algorithm creates feasible initial trajectories for the IDP method. The required experimental test-runs (Ho and Kim, 2013; Ho and Kim, 2014), proved HS and IDP cooperation results in better and quicker generation of initial solutions. The interaction of the algorithms includes two phases:

In the first phase, the HS generates a pre-defined number of feasible solutions. These initial solutions are used by the IDP as the initial trajectories and the process is repeated until the stopping criterion is satisfied. Although the HS uses monthly water releases $\left(R e_{j}\right)$ as decision variables, IDP uses the storage volume of the reservoir $\left(S_{j}\right)$ at the end of each month. This explains why Releases need to be transformed to the corresponding storage values (Figure 2).

\subsubsection{Hybrid HS-IDP-GA}

In addition to the above formation, the created variant HS-IDP-GA combines HS-IDP with GA, aiming to further improve the detected solutions. Similarly to HS-IDP, a transformation in the decision variables is required. This is not equal to combining HS-IDP with a GA, but it is an essentially distinct hybrid variant.

Accordingly the HS-IDP-GA algorithm operates in 4 phases. Similar to HS-IDP, the HS generates a predefined number of feasible solutions. In the second step, an iteration process initiates, where the IDP uses the created solutions as initial trajectories. The iterative process that will eventually converge to the best values in the HS-IDP-GA variant includes two additional steps. In the third step, a GA combines two of the IDP-detected solutions, using selection and crossover mechanisms. These solutions act as parents and generate two new solutions. If the offspring are better than the parents, they are selected in the fourth step as initial trajectories of the next iteration. This process is repeated until the stopping criterion is satisfied. 


\subsubsection{Hybrid HS-IDP-HS}

HS-IDP-HS has an identical structure with HS-IDP-GA, and is an additional, distinct hybrid variant of the proposed technique. Compared to the HS-IDP-GA it only differs in the third step of the iteration process, where HS is used instead of GA. In that step, HS selects the superior solutions included in the IDP's memory in order to generate new, hopefully better solutions (harmonies). Subsequently, in the fourth step the best harmonies are selected as the initial trajectories for the IDP of next iteration of the optimization process.

\subsection{Reservoir scheduling model}

\subsubsection{Objective function}

Hydroelectric dams use the energy of falling water through turbines that drive generators. The energy thus generated is calculated using Equation 3:

$$
E_{j}=9.81 \cdot n \cdot R e_{j} \cdot H_{j} \cdot \Delta t / 10^{6}
$$

$\mathrm{n}$ : Overall energy production efficiency (estimated $=0.82$ )

$\mathrm{Re}_{\mathrm{j}}$ : Water release rate through turbines in the $\mathrm{j}^{\text {th }}$ period $\left(\mathrm{m}^{3} \mathrm{~s}^{-1}\right)$

$H_{j}$ : Available hydraulic head in the $\mathrm{j}^{\text {th }}$ period $(\mathrm{m})$

$\Delta \mathrm{t}$ : Time step (=1 month $=732 \mathrm{~h}$ )

\section{$\mathrm{j}: 1, \ldots, 12$ (months from October-September)}

In planning the operation of a hydropower plant, the aim is the maximization of the total benefit derived from selling the produced energy to the National Grid. This is the objective function of the application, and it is calculated by multiplying the monthly hydropower generation with the corresponding electric energy prices:

$$
\max F=\sum_{j=1}^{12} E_{j} \cdot p_{j}
$$

$E_{j}$ : Produced energy in the $j^{\text {th }}$ period (GWh)

$\mathrm{p}_{\mathrm{j}}$ : Energy price in the $\mathrm{j}^{\text {th }}$ period ( $\$$ US $/ G W h$ ).

\subsubsection{Constraints}

The created algorithms seek the decision variable values that maximize the objective function, while satisfying the problem's constraints. Thus, it is ensured that the detected optimal strategies comply with relevant regulations and physical constraints:

1. Discharge constraint:

$\mathrm{Q}_{\min } \leq \operatorname{Re}_{\mathrm{j}}+\mathrm{O}_{\mathrm{j}} \leq \mathrm{Q}_{\max }$

$\mathrm{Q}_{\text {min }}$ : Minimum required discharge (Environmental Flow $-\mathrm{m}^{3} \mathrm{~s}^{-1}$ )

$\mathrm{Q}_{\max }$ : Maximum allowed discharge (Flood Mitigation $-\mathrm{m}^{3} \mathrm{~s}^{-1}$ ).

2. Storage volume constraints:

$$
\mathrm{S}_{\min } \leq \mathrm{S}_{\mathrm{j}} \leq \mathrm{S}_{\max }
$$

$\mathrm{S}_{\min } / \mathrm{S}_{\max }:$ Min/Max allowed storage volume $\left(10^{6} \mathrm{~m}^{3}\right)$

3. Overflow constraint:

$$
\mathrm{O}_{\mathrm{j}}=\mathrm{S}_{\mathrm{j}-1}+\mathrm{I}_{\mathrm{j}} \times \Delta \mathrm{t}-\mathrm{S}_{\max }^{\text {spillway }}-\mathrm{Re}_{\mathrm{j}} \times \Delta \mathrm{t}
$$


$\mathrm{O}_{\mathrm{j}}$ : Monthly water release in the $\mathrm{j}^{\text {th }}$ period via spillway $\left(10^{6} \mathrm{~m}^{3}\right)$

$S_{\max }^{\text {spillway }}$ : Max storage volume before overflow

The mass balance equation describing the annual reservoir operation is:

$$
S_{j}=S_{j-1}+l_{j} \times \Delta t-E v_{j}-R e_{j} \times \Delta t-O_{j}-I f_{j}
$$

$E v_{j}$ : Monthly Evaporation of reservoir's water in the $\mathrm{j}^{\text {th }}$ period $\left(10^{6} \mathrm{~m}^{3}\right)$.

$\mathrm{l}_{\mathrm{j}}$ : Monthly inflows into the reservoir in the $\mathrm{j}^{\text {th }}$ period $\left(\mathrm{m}^{3} \mathrm{~s}^{-1}\right)$.

If $\mathrm{j}$ : Infiltration of reservoir's water in the $\mathrm{j}^{\text {th }}$ period $\left(10^{6} \mathrm{~m}^{3}\right)$.

$\mathrm{S}_{\mathrm{j}-1} \& \mathrm{~S}_{\mathrm{j}}$ : Storage volumes at the beginning and the end of period $\mathrm{j}\left(10^{6} \mathrm{~m}^{3}\right)$

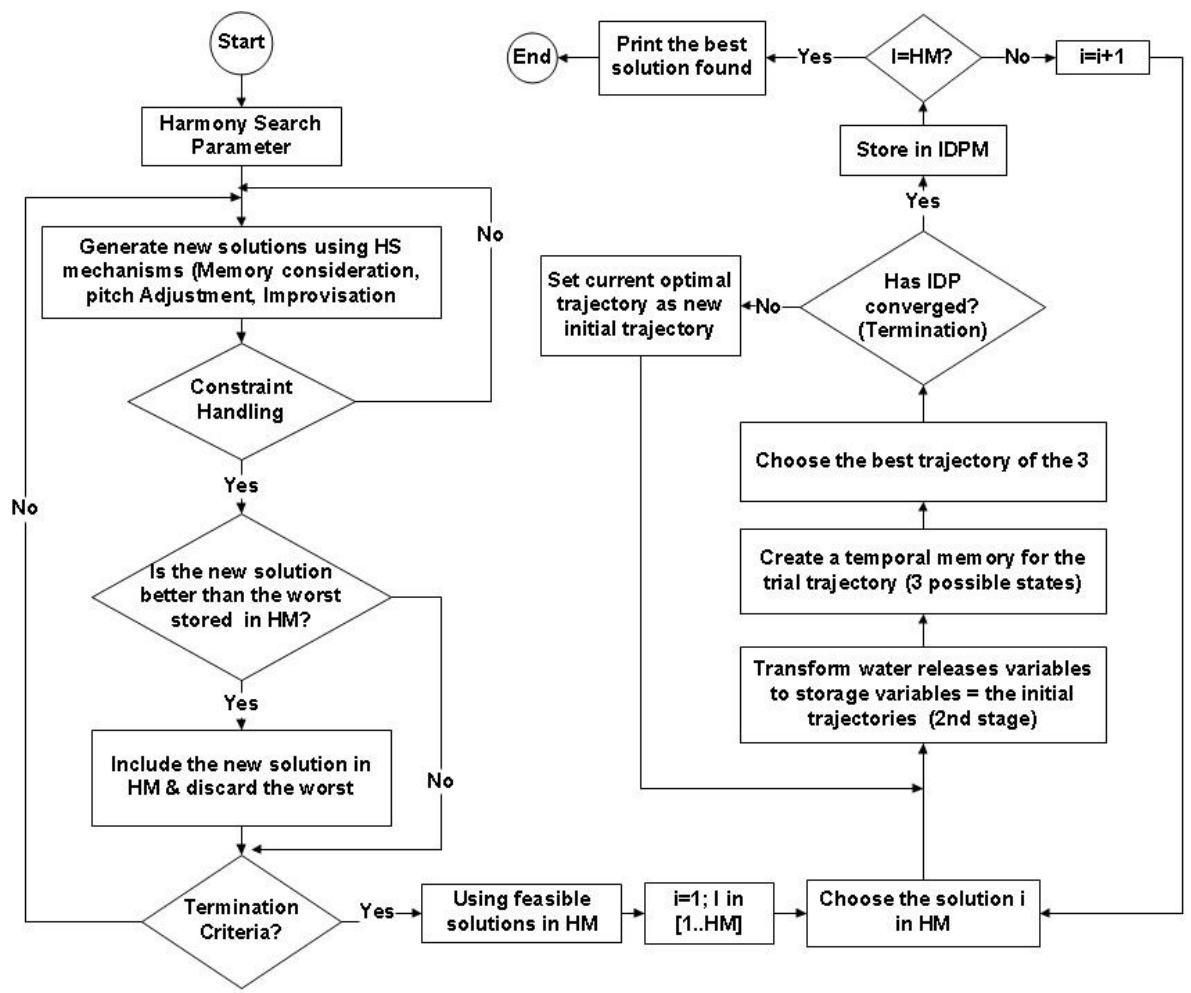

Figure 2. Flowchart of the created hybrid optimization algorithm (HS-IDP)

\section{Reservoir planning under environmental changes}

\subsection{Climate change}

One of the main challenges of reservoir planning is the development of a framework that corresponds to the changing status of river basins. Climate change is expected to significantly affect water resources, since changes in precipitation patterns are expected to affect water availability and runoff directly, while changes in temperature, radiation and humidity have an effect on evapotranspiration (Pechlivanidis et al., 2011).

In the present study the authors studied three different climate change scenarios $A 1, B 1$, and $B 2$, trying to align with the framework developed by the Institute of Meteorology, Hydrology and Environment (IMHEN, 2010) in Vietnam. The B1 emission scenario is a low-emissions scenario, while B2 is the mediumemissions scenario and A2 is the business-as-usual scenario. Recorded data from 1980-1999 were used for calibrating the model, before estimating future meteorological data (2020-2039) for the studied 
region of Vietnam.

\subsection{Air temperature data}

According to all scenarios, the temperature is expected to increase. B2 scenario predicts annual mean temperature increases of $0.6-1.5^{\circ} \mathrm{C}$ for the mid-2 $21^{\text {st }}$ century and $1.7-2.7^{\circ} \mathrm{C}$ for the second half of $21^{\text {st }}$ century. Scenario $\mathrm{A} 2$, as expected, predicts a higher increase $\left(0.9-1.5^{\circ} \mathrm{C}\right)$ for the mid- $21^{\text {st }}$ century and $1.9-$ $3.5^{\circ} \mathrm{C}$ for the late- $21^{\text {st }}$ century (Table $1 \mathrm{a}$ ).

Table 1. Generated climate data for Huong Dien basin (year 2020)

\begin{tabular}{|c|c|c|c|c|c|c|c|c|c|c|c|c|}
\hline \multicolumn{13}{|c|}{ a. Air temperature $\left({ }^{\circ} \mathrm{C}\right)$} \\
\hline Month & Oct. & Nov. & Dec. & Jan. & Feb. & Mar. & Apr. & May & Jun. & Jul. & Aug. & Sep. \\
\hline A2 & 19.2 & 19.0 & 24.0 & 24.9 & 26.0 & 25.7 & 26.8 & 26.0 & 24.0 & 23.5 & 21.5 & 19.8 \\
\hline B1 & 19.3 & 19.1 & 24.1 & 25.1 & 26.3 & 25.7 & 26.7 & 26.0 & 24.0 & 23.5 & 21.6 & 19.9 \\
\hline B2 & 19.2 & 19.0 & 24.0 & 24.9 & 26.0 & 25.6 & 26.8 & 26.0 & 24.0 & 23.4 & 21.5 & 19.8 \\
\hline \multicolumn{13}{|c|}{ b. Evaporation ( $\mathrm{mm} /$ month) } \\
\hline Month & Oct. & Nov. & Dec. & Jan. & Feb. & Mar. & Apr. & May & Jun. & Jul. & Aug. & Sep. \\
\hline A2 & 39.7 & 15.7 & 17.2 & 87.2 & 224.2 & 353.0 & 124.8 & 124.4 & 920.3 & 1044.3 & 972.5 & 197.4 \\
\hline B1 & 39.4 & 15.5 & 16.9 & 86.9 & 224.1 & 353.4 & 125.0 & 124.4 & 920.8 & 1047.4 & 975.7 & 197.1 \\
\hline B2 & 39.9 & 15.7 & 17.5 & 87.4 & 224.3 & 352.8 & 124.7 & 124.1 & 919.9 & 1042.3 & 971.1 & 197.6 \\
\hline \multicolumn{13}{|c|}{ c. Precipitation ( $\mathrm{mm} /$ month) } \\
\hline Month & Oct. & Nov. & Dec. & Jan. & Feb. & Mar. & Apr. & May & Jun. & Jul. & Aug. & Sep. \\
\hline A2 & 69.3 & 41.2 & 34.9 & 57.0 & 35.5 & 126.6 & 114.0 & 146.2 & 94.1 & 163.6 & 142.3 & 38.3 \\
\hline B1 & 69.5 & 41.5 & 35.1 & 57.3 & 35.7 & 129.0 & 116.6 & 151.0 & 94.2 & 162.8 & 142.2 & 38.0 \\
\hline B2 & 69.0 & 41.1 & 34.7 & 56.9 & 35.5 & 126.2 & 113.6 & 145.3 & 93.5 & 163.2 & 142.6 & 38.2 \\
\hline
\end{tabular}

\subsection{Reservoir's water evaporation}

Thornthwaite (1948) suggests the calculation of the potential evaporation (E, mm/month) at a monthly time step using air temperature as the input. Following $\mathrm{Xu}$ and Singh (2001), the annual heat index, I, is calculated as the sum of the monthly heat indices $i$, each of which is a function of the mean monthly air temperature $T_{m}$ (Equation 9):

$$
\begin{aligned}
& i=\left(\frac{T_{m}-273.16}{5}\right)^{1.51} \\
& E v=\frac{16 d}{360} \cdot\left(\frac{10 \cdot\left(T_{m}-273.16\right)}{l}\right)^{a}
\end{aligned}
$$

Where: I: Annual heat index, Ev: Potential evaporation

$\mathrm{T}_{\mathrm{m}}$ : mean monthly air temperature

$a=0.49+0.0191+0.00007711^{2}+0.0000006751^{3}$

$\mathrm{d}=$ total monthly sunshine hours

It is worth mentioning that the correlation between the observed and calculated Ev values (Table $1 \mathrm{~b}$ ) is high for all three observation stations $\left(R^{2}=0.85-0.97\right)$.

\subsection{Rainfall data}

According to the climate model, rainfall patterns will change in Hue basin during the $21^{\text {st }}$ century. It will increase in the wet period and decrease during the dry season (Table 1c). The trend of that change depends on the geographical location of river basins.

\subsection{Rainfall-Runoff model in the studied river basin}

The meteorological data need to be linked to the hydrology of the studied area. Thus, the seasonal tank 
model proposed by Paik (2005) has been used for the creation of the rainfall/runoff hydrographs, as illustrated in Figure 3.

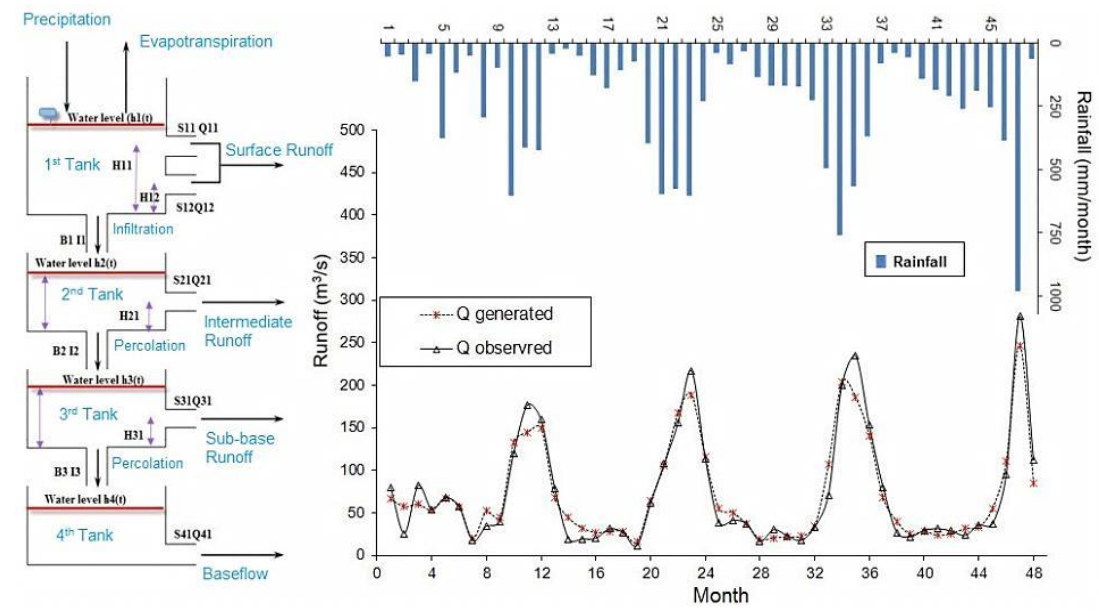

Figure 3. Tank model and created/observed Rainfall/Runoff Hydrographs (2001-2004)

The created model followed the season particularities of Vietnam and thus it included two seasons: the rain period that lasts from September to February and the dry period between March and August. The calibration of the rainfall-runoff model requires a minimization of the difference between estimated and observed values. Observed values included precipitation data and measurements of 29 consecutive years (1977-2005). The mean annual inflows as well as their frequency distribution are presented in Figure 4.

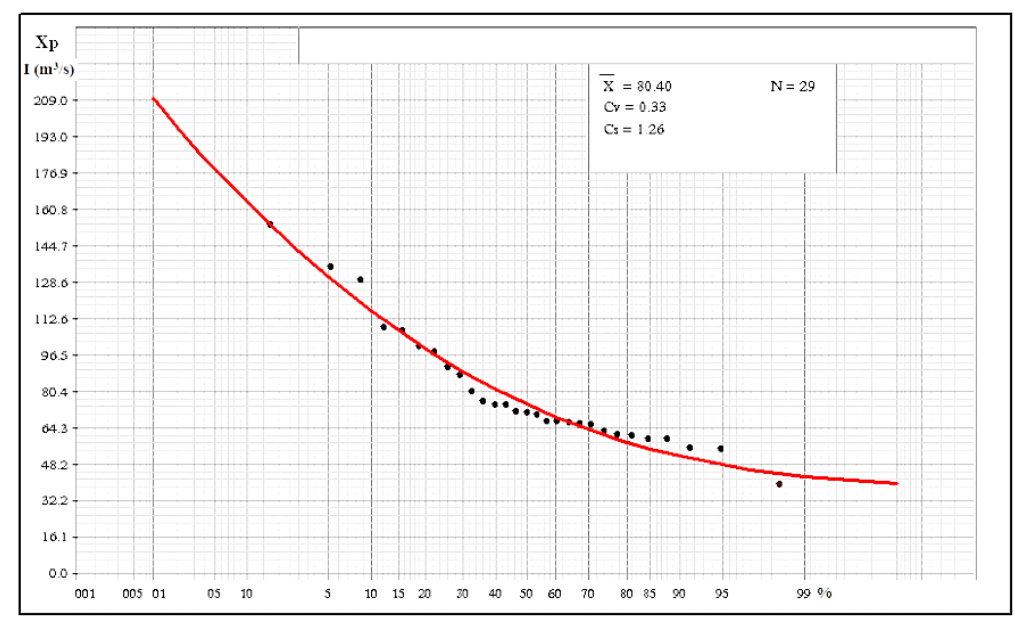

Figure 4. Mean annual inflows and the corresponding frequency distribution (1977-2005)

Hence, the rainfall-runoff model was validated on a representative dataset that included measurements of almost three decades. In the current literature scientists have performed data validation using stochastic simulation, in order to promote accuracy and generalization. This is presented in the work of Koutsoyiannis and Economou (2003) where the management of a multiple reservoir system using classical dynamic programming is compared to the management practices previously dictated by the parametric operating rule (Nalbantis and Koutsoyiannis, 1997).

This was implemented by detecting the optimal parameters of the seasonal tank model, using a simple HS algorithm. The accuracy of the model was confirmed using standard statistical indexes (SSq $=12387$, $P E V=0.44$, Nash-Sutcliffe $=0.937$ ). The efficacy of the calibration of the Rainfall-Runoff model is illustrated in Figure 3 (years 2001-2004). 


\subsection{Inflows to the Huong Dien reservoir}

Precipitation data for the years 2020-2039 have been created for three different scenarios, based on the measurements (1997-2005). The created precipitation data have been linked to the seasonal tank model in order to estimate future inflow scenarios into the HD reservoir. Rainfall on the HD watershed results in a direct runoff, where water is combined with the rivers' base flow and other water sources.

Indicatively, data generated for the year 2020 follow the same trend as the observed flow of the year 2000 (Fig.5). It is interesting to note that all scenarios estimate a small decrease in the total annual inflows $(\approx 5 \%)$. Contrary to this, they also calculate larger inflows for September. This inaccuracy, illustrated in Fig.5, appears in all scenarios and illustrates a weakness of the climate model.

\section{Case study: Huong Dien reservoir, central Vietnam}

By the end of 2005 the total installed generation capacity in Vietnam (11340 MW) was dominated by hydropower (39\%). The target for the year 2015 is to maintain the dominance of hydropower at $40 \%$, while aggressively developing gas production. Better planning and management of hydropower dams in Vietnam can soothe certain issues and problems.

The developed ORO model was applied to the Huong Dien reservoir in the Bo river basin (area: $707 \mathrm{~km}^{2}$ ). The Bo River has a total length of $85 \mathrm{~km}$ and receives the water released from the HD reservoir. Downstream, Bo joins the Huong River, the main river of the Hue Basin, and flows toward the sea. The latest planning policy predicts a mean annual energy production of $226.31 \mathrm{GWh}$ (Table 2), valued at $\$ 8.68$ million.

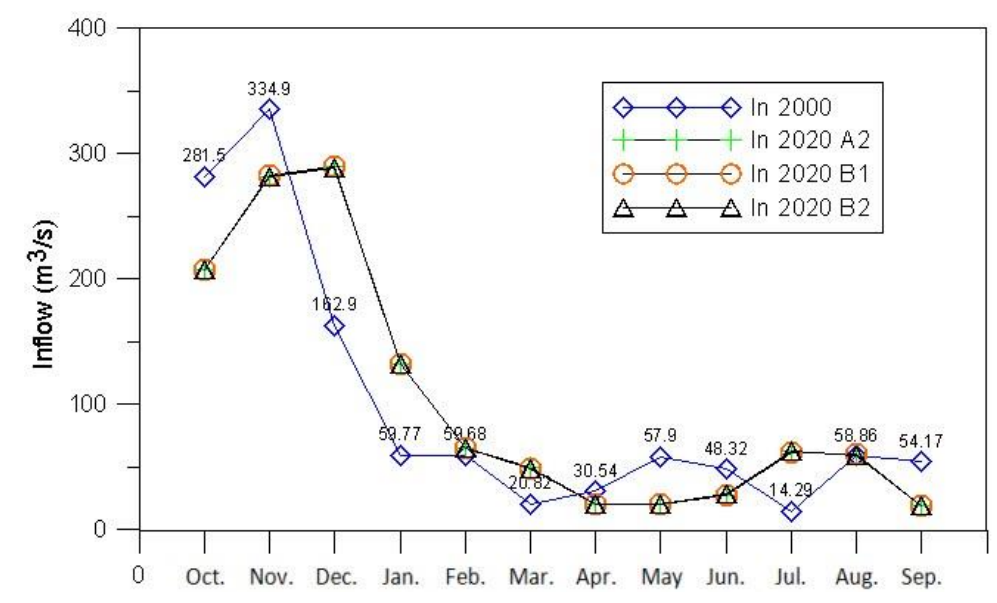

Figure 5. Observed (2000) and estimated inflows (2020) into Huong Dien reservoir

Table 2. Huong Dien Dam

\begin{tabular}{cc}
\hline Parameters & Quantity \\
\hline Max Dam Elevation: & $59.3 \mathrm{~m}$ \\
\hline Turbines Elevation: & $2.12 \mathrm{~m}$ \\
\hline Max storage volume: & $882.04 \mathrm{hm}^{3}$ \\
\hline Net storage volume: & $822.5 \mathrm{hm}^{3}$ \\
\hline Installed Capacity: & $54 \mathrm{MW}$ \\
\hline Mean Annual Energy Production: & $226.31 \mathrm{GWh}$ \\
\hline Annual Rainfall: & $3160 \mathrm{~mm}$ \\
\hline Mean river flow: & $80.4 \mathrm{~m}^{3} \mathrm{~s}^{-1}$ \\
\hline Mean Temperature: & $25.1^{\circ} \mathrm{C}$ \\
\hline Mean annual Evapotranspiration: & $79.4 \mathrm{~mm}$
\end{tabular}




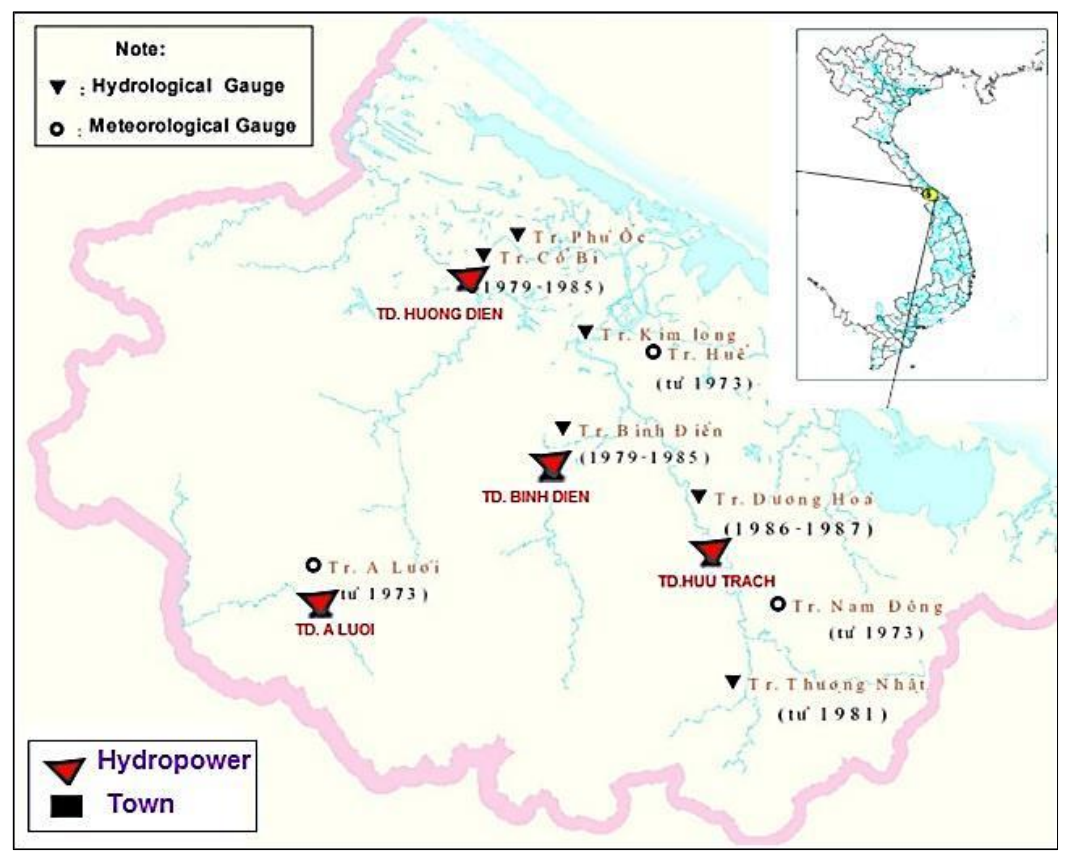

Figure 6. The area of the river basin in Vietnam

\subsection{Electricity cost}

The actual tariff applicable in Vietnam has been used in the present study. According to this, energy producers sell the generated energy at a higher price during February-June $(\$ 0.04 / \mathrm{KWh})$ whereas from July to January the price is slightly lower (\$0.037/KWh).

\subsection{Operating rules and constraints for Huong Dien reservoir}

Huong Dien Reservoir has some limitations in its max/min storage and water release rate (Table 2). These are safety measures for the dam, the environment and machinery.

- Release via Turbines: $23.61 \leq \operatorname{Re}_{\mathrm{j}} \leq 248.8\left(\mathrm{~m}^{3} \mathrm{~s}^{-1}\right)$

- Storage volume: $261.58 \cdot 10^{6} \leq \mathrm{S}_{\mathrm{j}} \leq 882.04\left(\mathrm{~m}^{3}\right)$

- Releases via Spillway and Turbines: $23.61 \leq \mathrm{Re}_{\mathrm{j}}+\mathrm{O}_{\mathrm{j}} \leq 488.6\left(\mathrm{~m}^{3} \mathrm{~s}^{-1}\right)$

Given that irrigation water demand is less between October and January, the Huong Dien reservoir increases gradually its storage during this period. From February to September, stored water covers agricultural demands and hydropower generation is reduced.

\subsection{Results and Discussion}

\subsubsection{Analysis of historic data}

An initial parameter calibration of the algorithms (HS, IDP, GA) was implemented to ensure efficient performance of each component. It is described in detail in Ho and Kim (2013).

Then, subsequent runs of the created hybrid method and its variants were performed. In each run Harmony Search completed an initial number of 5000 evaluations and generated a set of feasible initial solutions. Subsequently, each hybrid method (HS-IDP; HS-IDP-HS; HS-IDP-GA) completed 250000 calculations in order to optimize the objective function. A "classic" HS was also included for comparison. Each hybrid algorithm and the HS performed equal number of calculations. The computation time for each run ranged between 110-200 seconds. Coding the algorithms in Visual C++ proved to be effective. 


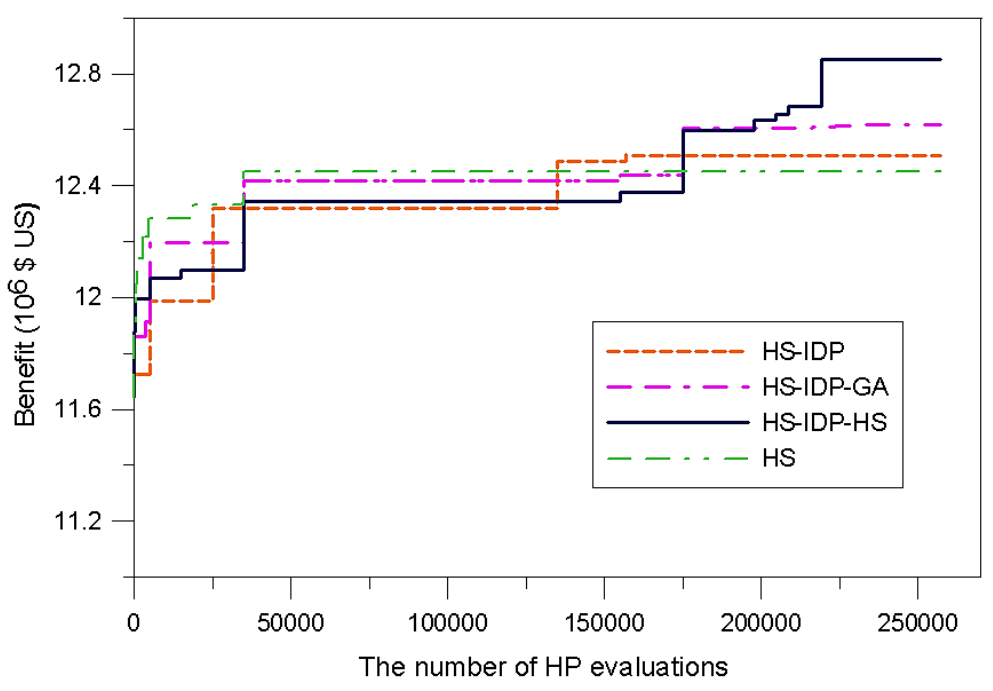

Figure7a. Optimization of current operation

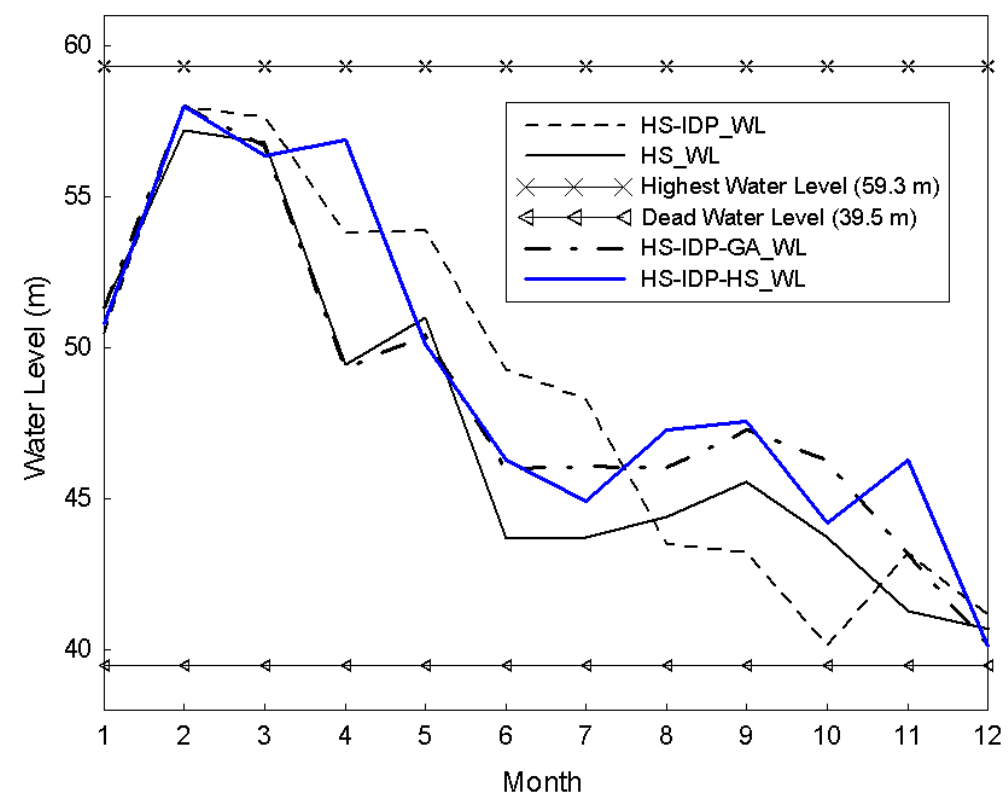

Figure 7b. Optimal water level curves

The convergence of all four methods is shown in Figure 7a, where it is clear that the created hybrid methods improve the performance of "classic" HS. HS-IDP-HS converged to the maximum benefit (339.6GWh, \$US 12.8521.106), while satisfying all constraints. HS-IDP-GA provided lower benefit (334.4GWh, \$US 12.617.106), while HS-IDP $\left(330.1 \mathrm{GWh}\right.$, \$US $\left.12.508 \cdot 10^{6}\right)$ and HS $(327.2 \mathrm{GWh}$, \$US $12.4608 \cdot 10^{6}$ ) provided similar, even lower results. The best solutions the algorithms detected correspond to final water storage (September) higher than the lower limit (Figure 7b).

Additional results corresponding to all three climate scenarios and for all hybrid methods are available in Ho and Kim (2013). The optimal solutions detected in the present study have substantially increased the obtained benefit over the previous strategy.

\subsubsection{Analysis of future scenarios: Environmental change}

The ORO for the year 2020 has been calculated for three different inflow scenarios (A2, B1, and B2). To this end, the authors used the hybrid algorithm that offered the best results in the previous analysis (i.e., HS-IDP-HS). 


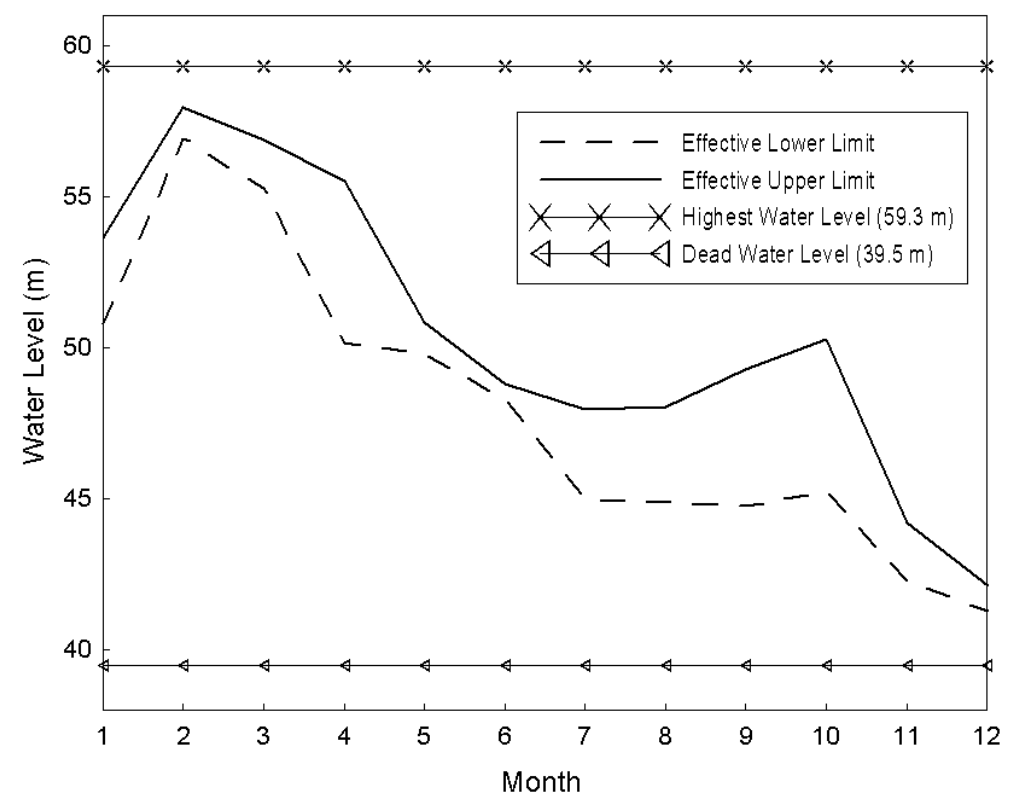

Figure 8. Effective water level range (2020)

Accordingly to each climate change scenario, the created hybrid method converged to different optimum management. The best strategy for scenario A2 converged to an annual production of 338.1GWh (\$US $\left.12.854 \cdot 10^{6}\right)$. When the $B 1$ scenario was presumed, the best strategy resulted to a maximum production of $345.3 \mathrm{GWh}$ (\$US $13.0169 \cdot 10^{6}$ ). Similarly, for B2 scenario, HS-IDP-HS yielded a solution generating 337.4GWh (\$US 12.8311.106).

It is obvious that the results of different climate change scenarios create lower and upper limits for the reservoir level. These limits (Figure 8 ) show the effective range of the water level and imply the corresponding water release rates. They are created by combining the $\mathrm{min} / \mathrm{max}$ values from the best solutions for all scenarios and can be considered as good operation curves for the year 2020. Thus, they can be used to address uncertainty in the management practices and serve as a guideline for the reservoir's long-term management towards productivity and risk management. Planning the future releases in accordance to these limits is expected to result to an effective and sustainable reservoir operation.

\section{Conclusions}

Reservoir operation and management play a major role in water resources planning. Therefore, the present study optimized a reservoir operation model using novel hybrid optimization algorithms. The created techniques converged to effective solutions for the objective function of hydropower production, while satisfying the problem's constraints.

The aim of the present research was to include the effect of environmental changes in the optimization process. Thus, the input of future data, generated using climate models, resulted in a more holistic planning of the Huong Dien reservoir. Moreover, a reduction of the uncertainties that climate models impose, has been attempted by considering three different scenarios that highlight different economical/environmental conditions.

The created hybrid algorithms were proven as robust tools, converged to excellent operation policies, and showed improved performance, when compared with simple metaheuristics and the current reservoir's policy. Therefore, their application to other reservoir operation problems can be successful.

Regarding the future operation of Huong Dien reservoir, there is a potential for installing an additional 27-MW turbine. In that case, the hydropower station will operate with three turbines and a total capacity of $81 \mathrm{MW}$. A similar study can examine the effects of this alteration on the future management of the 
reservoir.

\section{Acknowledgement}

This work was supported by a National Research Foundation of Korea (NRF) grant funded by the Korea government (MSIP) (No. 2013R1A2A1A01013886).

\section{References}

Afshar A., Haddad B.O., Marino M.A. and Adams B.J. (2007), Honey-bee mating optimization (hbmo) algorithm for optimal reservoir operation, Journal of the Franklin Institute, 344(5), 452-462.

Chow V.T. and Cortes Rivera (1974), Applications of DDDP in water resources planning, Research Report 78, University of Illinois, Water Resources Center, Urbana.

Efstratiadis A. and Koutsoyiannis D. (2008), Fitting hydrological models on multiple responses using the multiobjective evolutionary annealing-simplex approach, Practical Hydroinformatics, Springer Berlin Heidelberg, 259-273, 2008.

Geem Z.W., Kim J.H. and Loganathan G.V. (2001), New heuristic optimization algorithm: Harmony search, Simulation, 76(2), 60-68.

Geem Z.W. (2006), Optimal cost design of water distribution networks using harmony search, Engineering Optimization, 38.03, 259-277.

Hall W.A. and Shepherd R.W. (1967), Optimum operations for planning of a complex water resources system. Tech.Rep. 122 (UCLA-ENG 67-54), Water Resources Center, Univ. of California.

Hall W.A., Butcher W.S. and Esogbue A. (1968), Optimization of the operation of a multiple-purpose reservoir by dynamic programming, Water Resources Research, 4(3), 471-477.

Hejazi M.I., Cai X. and Ruddell B. (2008), The role of hydrologic information in reservoir operation-Learning from historical releases, Advances in Water Resources, 31(12), 1636-1650.

Ho V.H. and Kim J.H. (2013) Efficient use of water resources in reservoir using hybrid optimization algorithms. MSc Thesis, Korea University, Seoul City, South Korea.

Ho V.H. and Kim J.H. (2014). Improvement of reservoir operation by hybrid optimization algorithm: Case study of Huong Dien reservoir, Vietnam. In: IAHS Red Book No.363: Hydrology in a Changing World: Environmental \& Human Dimensions, Montpellier, France.

Holland J.H. (1975), Adaptation in natural and artificial systems: An introductory analysis with applications to biology, control, and artificial intelligence. U Michigan Press.

IMHEN Viet Nam, (11/2010). Impact of climate change on water resources and adaptation measurement. Final Report.

Karamouz M., Houck M.H. and Delleur J.W. (1992), Optimization and simulation of multiple reservoir systems, Journal of Water Resources Planning \& Management, 118(1), 71-81.

Kim J.H., Geem Z.W. and Kim E.S. (2001), Parameter estimation of the nonlinear Muskingum model using harmony search, Journal of the American Water Resources Assoc., 37(5), 1131-1138.

Kougias I. and Theodossiou N. (2013), Application of the harmony search optimization algorithm for the solution of the multiple dam system scheduling, Optimization and Engineering, 14(22), 331-344.

Koutsoyiannis D. and Economou A. (2003), Evaluation of the parameterization-simulation-optimization approach for the control of reservoir systems, Water Resources Research, 39(6), 1170.

Kumar D.N. and Reddy M.J. (2006), Ant colony optimization for multi-purpose reservoir operation, Water Resources Management, 20(6), 879-898.

Larson R.E. (1968) State increment dynamic programming. Elsevier, New York.

Larson R.E. and Keckler W.G. (1969), Applications of dynamic programming to the control of water resource systems, Automatica, 5(1), 15-26.

Mantawy A.H., Soliman S.A. and El-Hawary M.E. (2003), An innovative simulated annealing approach to the longterm hydroscheduling problem, International Journal of Electrical Power \& Energy Systems, 25(1), 41-46.

Murray D.M. and Yakowitz S.J. (1979), Constrained differential dynamic programming and its application to multireservoir control, Water Resources Research, 15(5), 1017-1027. 
Nalbantis I. and Koutsoyiannis D. (1997), A parametric rule for planning and management of multiple reservoir systems, Water Resources Research, 33(9), 2165- 2177.

NCCSAP (2005) Climate change impact in Huong River basin and adaption in its coastal district PhuVang, HueVietnam. Project Work Plan, Netherlands Climate Assistance Program, pp.1-27.

Paik K., Kim J.H., Kim H.S. and Lee D.R. (2005), A conceptual rainfall-runoff model considering seasonal variation, J. Hydrol. Process, 19, 3837-3850.

Pechlivanidis I.G., Jackson B.M., McIntyre N.R. and Wheater H.S. (2011), Catchment scale hydrological modelling: a review of model types, calibration approaches and uncertainty analysis methods in the context of recent developments in technology and applications, Global NEST Journal, 13(3), 193-214.

Stedinger J.R., Sule B.F. and Loucks D.P. (1984), Stochastic dynamic programming models for reservoir operation optimization, Water Resources Research, 20(11), 1499-1505.

Thornthwatie, CW (1948) An approach toward a rational classification of climate. Geographical Review (January).

Tospornsampan J., Kita I., Ishii M. and Kitamura Y. (2005), Optimization of a multiple reservoir system operation using a combination of genetic algorithm and discrete differential dynamic programming: a case study in Mae Klong system, Thailand, Paddy and Water Environment, 3(1), 29-38.

Turgeon A (1981), A decomposition method for the long-term scheduling of reservoirs in series, Water Resources Research, 17(6), 1565-1570.

UN Situation Report (2013). Viet Nam: Flooding in Central provinces. Situation Report No.1 (20 November 2013).

Vietnam Meteorology, Hydrology Center (2005) Hue Province Meteorological Annual Statistical Datasets Report (1977-2005).

Wardlaw R. and Sharif M. (1999), Evaluation of genetic algorithms for optimal reservoir system operation, Journal of water resources planning and management, 125(1), 25-33.

Xu C.Y. and Singh V.P. (2001), Evaluation and generalization of temperature-based equations for calculating evaporation, Hydrol. Processes, 15, 305-319. 